\title{
Epidemiology of anorexia nervosa in a French community-based sample of 39,542 adolescents
}

\author{
Nathalie T. Godart ${ }^{1,2}$, Stéphane Legleye $e^{1,3}$, Caroline Huas ${ }^{1,4}$, Sylvana M. Cotée ${ }^{1,5}$, Marie Choquet ${ }^{1}$, \\ Bruno Falissard $^{1,5}$, Evelyne Touchette ${ }^{1,5,6}$ \\ ${ }^{1}$ Unit 669 INSERM, University of Paris-Sud and University of Paris Descartes, UMR-S0669, Paris, France \\ ${ }^{2}$ Psychiatry, Institut Mutualiste Montsouris, Paris, France \\ ${ }^{3}$ Institut National des Études Démographiques (INED), Paris, France \\ ${ }^{4}$ Department of General Practice, University of Tours, Tours, France \\ ${ }^{5}$ International Laboratory for Child and Adolescent Mental Health (Unit 669 INSERM, Paris, France and Research Unit on Chil- \\ dren's Psychosocial Maladjustment, University of Montreal, Montreal, Canada) \\ ${ }^{6}$ École de Psychologie, Université Laval, Quebec City, Canada \\ Email: nathalie.godart@imm.fr, stephane.legleye@ined.fr, carohuas@gmail.com, sylvana.cote@umontreal.ca, \\ choquet.exinserm@yahoo.fr, falissard b@wanadoo.fr, evelynebolivie@hotmail.com
}

Received 27 February 2013; revised 31 March 2013; accepted 7 April 2013

Copyright (C) 2013 Nathalie T. Godart et al. This is an open access article distributed under the Creative Commons Attribution License, which permits unrestricted use, distribution, and reproduction in any medium, provided the original work is properly cited.

\begin{abstract}
Purpose: To assess the prevalence of DSM-IV anorexia nervosa criteria, anorexia nervosa and subthreshold subgroups, and their incidence between the ages of 12 and 17 years using Cole's international thinness cut-offs, and to characterize these anorexic adolescents by parental socioeconomic status and whether or not they reported receiving treatment. Method: In all, a representative sample of 39,542 French adolescents (19,658 girls and 19,884 boys) was recruited in a cross-sectional study in 2008. Anorexia nervosa DSM-IV diagnosis was determined by a self-administered questionnaire. Results: Among females, $0.5 \%(n=105)$ met criteria for anorexia nervosa between the ages of 12 and 17 years, whereas among males, the prevalence was $0.03 \%(n=6)$. In females, the prevalence of sub-threshold anorexia nervosa was found to be between $1.2 \%(n=216)$ and $3.3 \%(n=618)$; more than $75 \%$ were of the restrictive subtype. The highest incidence of anorexia nervosa was at 16 years. There was also a greater prevalence of sub-threshold anorexia nervosa subgroups among subjects with high parental socioeconomic status. More than half of the female adolescents who met the anorexia nervosa criteria reported receiving treatment for their disorder, versus $23 \%$ to $40 \%$ of the adolescents in the sub-threshold subgroups $(\mathrm{P}<$ 0.0001). Conclusions: This study is the first to report the prevalence of AN on such a large community sample of adolescents. Using Cole's international thin-
\end{abstract}

ness cut-off could improve international comparability among studies. Adolescents from the higher socioeconomic categories were more likely to be anorexic.

Keywords: Anorexia Nervosa; Prevalence; Incidence; Adolescence; Community Survey

\section{INTRODUCTION}

Anorexia nervosa (AN) is a severe psychiatric condition with high morbidity and mortality, and which severely disrupts the lives of patients and those around them [1,2]. The most recent epidemiological studies of AN yield estimates of prevalence ranging from $0.04 \%$ [3], $0.30 \%$ [4], $0.48 \%$ [5], $0.90 \%$ [6] to $2.20 \%$ [7]. These variations may be explained by 4 main factors. First, the sample included participants of various ages and nationalities. For example, the prevalence of $0.04 \%$ among 4746 American adolescents aged 14 and 15 years was found to be lower [3] than the prevalence of $0.30 \%$ found among 10,123 adolescents aged $13-18$ [4] and that of $0.90 \%$ found among 9282 American adults [6]. In Europe, the prevalence of AN among 4139 adults aged 18 or older was found to be $0.48 \%$ [5], versus $2.20 \%$ in a Finish national cohort of birth twins comprising 2881 adult women aged 22 - 28 years [7]. Second, the studies use a range of different AN measurement instruments, with only two being based on the same instrument (i.e., composite International Diagnostic Interview) $[5,6]$. Third, different weight cut-offs were used in the various studies; and fourth, no study had exactly the same definition for AN 
or broad AN.

There are four main limitations in the interpretation of previous findings. First, the majority of epidemiological studies have been conducted in adult populations with retrospective recall of age at onset, which led to underestimation of AN prevalence during adolescence among adults. Adolescents under age 18 years are usually excluded from large epidemiological studies, although half the AN cases appear before that age $[5,6,8]$. It is important to investigate adolescent populations before the age of 18 years in order to assess the first years following AN onset.

Second, most previous retrospective studies assessed history of AN in childhood and adolescence using the adult weight criterion for thinness, which led to overestimation of the number of underweight subjects. For adults, the cut-off usually recommended for underweight by the International Classifications of Diseases (ICD-10) [9] is $17.5 \mathrm{~kg} / \mathrm{m}^{2}$. For children and adolescents, the cutoff usually recommended is the $10^{\text {th }}$ percentile on the weight growth curve depending on age and height [10]. The use of the underweight cut-off for adults (i.e., 17.5 $\mathrm{kg} / \mathrm{m}^{2}$ ) corresponds to the $25^{\text {th }}$ and $50^{\text {th }}$ percentile at age 13 , which is over the $10^{\text {th }}$ percentile weight curve [11].

Third, none of these studies used an international reference for underweight to determine "criterion A" of the AN diagnosis based on DSM-IV (i.e., weight loss leading to maintenance of body weight below $85 \%$ of the expected weight). In order to obtain prevalence of AN that is comparable across countries, studies should use the same international definition for the BMI criterion taking account of sex and age. Cole et al. [12] determined 3 international cut-offs to define curves of thinness (i.e., grade 1 : $\mathrm{BMI}=16.0 \mathrm{~kg} / \mathrm{m}^{2}$, grade $2: \mathrm{BMI}=$ $17.0 \mathrm{~kg} / \mathrm{m}^{2}$, and grade $3: \mathrm{BMI}=18.5 \mathrm{~kg} / \mathrm{m}^{2}$ ) in children and adolescents, based on BMI at age 18 years. To our knowledge, no recent studies have used this definition of thinness to assess AN prevalence in a community sample. It would therefore be useful to apply international thinness criteria so that AN prevalence can be compared in future international studies [12]. Finally, the above studies are too small to accurately diagnose cases $(\mathrm{N}=1, \mathrm{~N}=$ $34, \mathrm{~N}=18, \mathrm{~N}=22$, and $\mathrm{N}=55$, respectively) [3-7] or to describe the prevalence of different subtypes of AN. For a rare disorder such as $\mathrm{AN}$, large samples provide us with more cases, and enable us to investigate the frequencies of restrictive and binge/purging AN subtypes.

In the present study, we investigate the prevalence of DSM-IV anorexia nervosa criteria, AN, sub-threshold AN subgroups and their subtypes (binge/purging or restrictive) among a very large $(\mathrm{n}=39,542)$ communitybased sample of female and male adolescents aged 17 years, using international criteria for thinness according to age and sex-specific cut-offs.

\section{METHODS}

\subsection{Study Design and Population}

Participants were recruited in metropolitan France (i.e. excluding overseas territories) between March $15^{\text {th }}$ and March $31^{\text {st }} 2008$ during the National Defence Preparation Day "Journée d'Appel de Préparation à la Défense" (JAPD) [13]. In all, 764,000 adolescents aged 17 years were living in metropolitan France in 2008 [14], and $44,833(5.9 \%)$ of these adolescents aged 17 years were invited to participate in the Survey on Health and Behavior: "Enquête sur la Santé et les Consommations lors de l'Appel de Préparation A la Défense", entitled ESCAPAD [13,15], a cross-sectional survey conducted by the French Monitoring Center for Drugs and Drug Addiction or "Observatoire Français des Drogues et des Toxicomanies" (OFDT), and administered during JAPD days in collaboration with the National Service Bureau of the Army. The participation rate for this survey was $99.8 \%$ (110 refused). The analyzed sample comprised 39,542 French adolescents (5181 were excluded for incomplete data), i.e. $88.2 \%$ of the subjects invited to participate in the survey $(\mathrm{n}=19,658$ girls and $\mathrm{n}=19,884$ boys). This represents $5.2 \%$ of adolescents aged 17 years living in metropolitan France. The survey obtained the public statistics general interest and statistical seal of quality from the "Comité National de l'Information Statistique" (CNIS) as well as the approval of the French data protection authority ("Commission nationale de l'informatique et des libertés" (CNIL).

\subsection{Description of Measures}

The ESCAPAD survey is a self-administered questionnaire which takes 35 minutes to complete. The response rates for socio-demographic characteristics and eating disorder questions were above $95 \%$. To identify subjects with eating disorders, a self-completion questionnaire was designed by a multidisciplinary group of researchers and clinicians specialized in eating disorders. The questions were designed to detect AN criteria based on DSMIV [16]. The questions had been previously tested on adolescents and anorexic patients to ensure that they were readily understandable.

The prevalence and incidence of AN and sub-threshold AN between the ages of 12 and 17 years were defined according to the following DSM-IV criteria [16]:

- Criterion A (Refusal to maintain body weight at or above a normal minimum weight for age and height (i.e., weight loss leading to maintenance of body weight below $85 \%$ of expected). The adolescent met the Criterion A if 1) he/she answered "yes" to this 
question: "Since your $12^{\text {th }}$ birthday, has there been a period when you lost a lot of weight or refused to gain weight?" and 2) if their BMI was below Cole's grade 2 cut-off for thinness $\left(B M I=17 \mathrm{~kg} / \mathrm{m}^{2}\right)$ according to gender and age [12]. The BMI was calculated from two questions: "During this period, what was your lowest weight?" and "During this period, how tall were you?"

- Criterion B (Intense fear of gaining weight or becoming fat, even though underweight) was met if the adolescent had a BMI below Cole's grade 2 thinness [12] and if they answered "yes" to this question: "Since your $12^{\text {th }}$ birthday, has there been a period when you were scared of gaining weight or becoming fat?"

- Criterion C (Disturbance in the way in which body weight or shape is experienced, undue influence of body shape on self-evaluation, or denial of the seriousness of the current low body weight) was met if the adolescent answered "yes" to this question: "Since your $12^{\text {th }}$ birthday, has there been a period when you felt uncomfortable with your weight and/or your shape?" This criterion was also met if the participant answered "no" to the question: "did you lose a lot of weight or refuse to gain weight" and "yes" to the question: "did people tell that you were too thin or that you looked anorexic?"

- Criterion D (Amenorrhea in postmenarcheal females) was met if the girls answered "yes" to the question: "has your menstrual cycle stopped at any time for at least 3 months (not including pregnancy)?"

AN binge/purging (AN-B/P) subtype was distinguished from $A N$ restrictive $(A N-R)$ subtype in the questionnaire. $\mathrm{AN}-\mathrm{B} / \mathrm{P}$ was assessed by the following questions.

"Since the age of 12 years, have you eaten very large amounts of food very quickly and been unable to stop eating (episode of binge eating)?" and "Have you had episodes of binge eating when you were too thin or when people said that you were too thin or that you looked anorexic?" The purging behaviors were assessed by: "Did you take laxatives/diuretics?" or "Did you vomit in order to avoid gaining weight? If AN girls answered "yes" to one of the above questions, they were considered in the AN-B/P subtype. The other AN adolescents were considered to belong to the AN restrictive subtype.

To be diagnosed as $\mathrm{AN}$, all $\mathrm{AN}$ criteria based on DSM-IV must be met. The three sub-threshold AN definitions for girls where: 1) $\mathrm{AN}(\mathrm{ABC})$ : $\mathrm{AN}$ criteria are met except for amenorrhea, as proposed by Attia et al. [17]; 2) sAN: AN criteria are met with a less severe BMI level for criterion $\mathrm{A}\left(\mathrm{BMI}=18.5 \mathrm{~kg} / \mathrm{m}^{2}\right)$; and 3) $\mathrm{sAN}(\mathrm{ABC})$ : AN criteria are met, except for amenorrhea, with a less severe BMI level for criterion A $\left(B M I=18.5 \mathrm{~kg} / \mathrm{m}^{2}\right)$. For boys, only one AN definition and one sub-threshold
sAN(ABC) could be defined because there was no amenorrhea criterion. To calculate the incidence of $\mathrm{AN}$ and sub-threshold AN, the age of onset was investigated retrospectively by this question: "how old were you at that time?"

Socioeconomic status (SES) is based on the higher of the parents' two occupational categories reported by the adolescent, according to the typology of the National Institute for Statistics and Economic Studies [18]. The categories were grouped into 4 levels: 1) managerial, or intellectual professions; 2) small to medium business owners or farmers; 3) manual, office or sales workers; and 4) unemployed.

\subsection{Statistical Analysis}

Statistical analyses were performed with SAS version 9.2.3 software which can be used to compute prevalence estimates and variance. To obtain a representative sample of the French population, a weighted score was calculated in order to match the latest French Census data as closely as possible for gender, age, and geographical region. The prevalence rates for $\mathrm{AN}$ and sub-threshold AN based on DSM-IV criteria were calculated by dividing the number of cases by the total number of subjects who answered the questionnaire. The age-specific incidence per 100,000 was calculated from new AN cases at each age divided by the number of adolescents at risk. The average annual incidence per 100,000 was calculated from all $\mathrm{AN}$ cases between the ages of 12 and 16 years divided by 5 years. T-tests and chi-square tests were used to compare adolescent characteristics between AN subgroups and controls. Differences were considered significant at $\mathrm{P}<0.01$.

\section{RESULTS}

\subsection{Sociodemographic Characteristics}

Table 1 shows the sociodemographic characteristics of the sample.

The mean for current BMI was between the $50^{\text {th }}$ and $75^{\text {th }}$ percentiles for boys and girls based on the Frenchgrowth curves of Rolland-Cachera et al. [11]. Of the whole sample, $6.4 \%$ of the adolescents had a current BMI below the $10^{\text {th }}$ percentile [11], 2.5\% had a BMI below Cole's grade 2 thinness criterion [12] and 13.2\% had a BMI below Cole's grade 3 thinness criterion [12].

\subsection{Prevalence}

Table 2 shows the prevalence of AN symptoms/criteria, AN diagnosis, and sub-threshold AN subgroups. The prevalence of criteria A and B is more than twice as high when Cole's grade 3 thinness criterion $\left(18.5 \mathrm{~kg} / \mathrm{m}^{2}\right)$ is used rather than Cole's grade 2 thinness criterion (17.0 
Table 1. Sociodemographic variables of the adolescent sample $(n=39,542)$.

\begin{tabular}{|c|c|c|c|}
\hline \multirow{2}{*}{ Demographic variables } & Girls & Boys & Total \\
\hline & $\%,(n=19,658)$ & $\%,(n=19,884)$ & $\%,(n=39,542)$ \\
\hline \multicolumn{4}{|l|}{ Adolescent variables } \\
\hline $\operatorname{Age}^{\mathrm{f}}$ & $17.4 \pm 0.3$ & $17.4 \pm 0.3$ & $17.4 \pm 0.3$ \\
\hline Current Body mass index ${ }^{\mathrm{t}}$ & $20.7 \pm 3.0$ & $21.5 \pm 2.9$ & $21.1 \pm 3.0$ \\
\hline Current Body mass index, $<17 \mathrm{~kg} / \mathrm{m}^{2^{*}}$ & 3.4 & 1.7 & 2.5 \\
\hline Current Body mass index $<10^{\text {th }}$ percentile $^{\S}$ & 7.7 & 5.2 & 6.4 \\
\hline Current Body mass index, $<18.5 \mathrm{~kg} / \mathrm{m}^{2 * *}$ & 18.6 & 8.2 & 13.2 \\
\hline \multicolumn{4}{|l|}{ Adolescent education } \\
\hline High school & 89.6 & 89.6 & 84.1 \\
\hline Vocational school, apprenticeship & 7.0 & 15.8 & 11.5 \\
\hline Out of school & 3.4 & 5.3 & 4.4 \\
\hline Grade repetition & 38.9 & 49.2 & 44.2 \\
\hline \multicolumn{4}{|l|}{ Parental occupational status } \\
\hline Managerial or intellectual professions & 37.2 & 35.6 & 36.4 \\
\hline Small to medium business owners or farmers & 18.2 & 19.4 & 18.8 \\
\hline Manual, office or sales workers & 32.3 & 32.4 & 32.8 \\
\hline Unemployed & 7.3 & 6.3 & 6.7 \\
\hline missing & 4.0 & 6.4 & 5.2 \\
\hline \multicolumn{4}{|l|}{ Familial variable } \\
\hline Structure, intact & 70.3 & 70.3 & 70.3 \\
\hline Living with parents & 90.6 & 89.7 & 90.2 \\
\hline \multicolumn{4}{|l|}{ Treatment variable } \\
\hline Receiving treatment or had been hospitalized for AN & 2.0 & 0.6 & 1.3 \\
\hline
\end{tabular}

${ }^{\mathrm{I}}$ means and standard deviation $( \pm \mathrm{sd})$ for continuous variables; "International Cole's thinness criteria grade 2 (2007); ${ }^{\S}$ Rolland-Cachera and her colleagues' BMI growth curves (1991); ${ }^{* *}$ International Cole's thinness criteria grade 3 (2007).

$\left.\mathrm{kg} / \mathrm{m}^{2}\right)[12]$. The prevalence of $\mathrm{AN}$ in girls is $0.5 \%(\mathrm{~N}=$ 105), 2 to 6 times lower than prevalence rates for the sub-threshold AN subgroups. Among boys, the prevalence rates of $\mathrm{AN}(\mathrm{ABC})(\mathrm{N}=6)$ and $\mathrm{sAN}(\mathrm{ABC})(\mathrm{N}=20)$ are very low.

Consequently, the following analyses were performed on girls only. We found that over $75 \%$ of the AN and sub-threshold AN subgroups were restrictive subtype. However, one boy reported AN-B/P subtype.

\subsection{AN Onset and Incidence}

More than $70 \%$ of AN and sub-threshold AN subgroups reported onset between the ages of 15 and 16 years. Figure 1 shows the age-specific incidence per 100,000 between ages 12 and 16 years by AN subgroups. For girls, we calculated an average incidence by AN subgroup of 97 per $100,000(95 \% \mathrm{CI}=77-117)$ person-years for $\mathrm{AN}$, 202 per $100,000(95 \% \mathrm{CI}=175-33)$ person-years for sAN, 245 per $100,000(95 \% \mathrm{CI}=216-280)$ personyears for $\mathrm{AN}(\mathrm{ABC})$, and 577 per 100,000 person-years
$(95 \% \mathrm{CI}=545-643)$ for sAN(ABC). For boys, we also calculated an average AN incidence by AN subgroup: 4 per 100,000 $(95 \% \mathrm{CI}=0-8)$ person-years for $\mathrm{AN}(\mathrm{ABC})$, and 17 per 100,000 person-years $(95 \% \mathrm{CI}=10-27)$ for sAN(ABC) (see Figure 1).

\subsection{Socio-Occupational Characteristics, Body Mass Index and Treatment Associated with AN Subgroups}

AN and sub-threshold AN subgroups were unequally distributed across SES categories (see Table 3).

We also calculated that girls included in $\mathrm{AN}(\mathrm{ABCD})$ subgroup were 1.83 times $(95 \% \mathrm{CI}=1.10$ - 3.03) more likely to come from families where the parents were in managerial or intellectual occupations rather than manual, office or sales workers or unemployed. Not surprisingly, girls included in AN and AN sub-threshold subgroups significantly more frequently reported receiving treatment or having been hospitalized for anorexia compared to adolescents who reported no anorexic problems $(\mathrm{P}<0.001)$. 
Table 2. Prevalence of AN Criteria, AN and sub-threshold AN based on DSM-IV definitions $(\mathrm{n}=39,542)$.

\begin{tabular}{|c|c|c|c|c|c|c|c|c|}
\hline \multirow[b]{3}{*}{ Anorexia Nervosa } & \multicolumn{4}{|c|}{ Girls $(\mathrm{n}=19,658)$} & \multicolumn{4}{|c|}{ Boys $(\mathrm{n}=19,884)$} \\
\hline & \multirow{2}{*}{$\begin{array}{c}\text { Frequency } \\
n\end{array}$} & \multicolumn{2}{|c|}{ Prevalence } & \multirow{2}{*}{$\begin{array}{c}\text { Missing } \\
n\end{array}$} & \multirow{2}{*}{$\begin{array}{c}\text { Frequency } \\
n\end{array}$} & \multicolumn{2}{|c|}{ Prevalence } & \multirow{2}{*}{$\frac{\text { Missing }}{n}$} \\
\hline & & $\%^{\mathrm{I}}$ & $(95 \% \mathrm{CI})$ & & & $\%^{\mathrm{f}}$ & $(95 \% \mathrm{CI})$ & \\
\hline \multicolumn{9}{|l|}{ DSM-IV criteria } \\
\hline \multicolumn{9}{|l|}{$\begin{array}{l}\text { A. Refusal to maintain body weight } \\
\text { over a minimal normal weight }\end{array}$} \\
\hline $17 \mathrm{~kg} / \mathrm{m}^{2 *}$ & 520 & 2.8 & $2.5-3.0$ & 112 & 38 & 0.2 & $0.1-0.3$ & 558 \\
\hline $18.5 \mathrm{~kg} / \mathrm{m}^{2 * *}$ & 1237 & 6.5 & $6.2-6.9$ & 112 & 95 & 0.5 & $0.4-0.6$ & 558 \\
\hline \multicolumn{9}{|l|}{$\begin{array}{l}\text { B. Intense fear of gaining weight } \\
\text { or becoming fat even though underweight }\end{array}$} \\
\hline $17 \mathrm{~kg} / \mathrm{m}^{2^{*}}$ & 359 & 1.9 & $1.7-2.1$ & 336 & 11 & 0.1 & $0.0-0.1$ & 723 \\
\hline $18.5 \mathrm{~kg} / \mathrm{m}^{2 * *}$ & 896 & 4.8 & $4.5-5.1$ & 336 & 36 & 0.2 & $0.1-0.3$ & 723 \\
\hline \multicolumn{9}{|l|}{$\begin{array}{l}\text { C. Disturbance in the way in which } \\
\text { one's body weight size or }\end{array}$} \\
\hline shape is experienced & 8089 & 42.6 & $41.8-43.3$ & 533 & 2956 & 15.4 & $14.8-15.9$ & 626 \\
\hline $\begin{array}{l}\text { D. Amenorrhea ( }>3 \text { missing menstrual cycles, } \\
\text { not including pregnancy) }\end{array}$ & 2283 & 12.2 & $11.7-12.7$ & 871 & nd & nd & nd & nd \\
\hline \multicolumn{9}{|l|}{ AN definitions } \\
\hline AN & 105 & 0.5 & $0.4-0.7$ & 871 & nd & nd & nd & nd \\
\hline sAN & 216 & 1.2 & $1.0-1.3$ & 871 & nd & nd & nd & nd \\
\hline $\mathrm{AN}(\mathrm{ABC})$ & 256 & 1.4 & $1.2-1.6$ & 860 & 6 & 0.0 & $0.0-0.1$ & 820 \\
\hline sAN(ABC) & 618 & 3.3 & $3.1-3.6$ & 860 & 20 & 0.1 & $0.1-0.2$ & 820 \\
\hline \multicolumn{9}{|l|}{ AN Restricting subtype } \\
\hline $\mathrm{AN}$ & 66 & 0.3 & $0.2-0.4$ & 873 & nd & nd & nd & nd \\
\hline sAN & 140 & 0.7 & $0.6-0.8$ & 877 & nd & nd & nd & nd \\
\hline $\mathrm{AN}(\mathrm{ABC})$ & 191 & 1.0 & $0.8-1.1$ & 863 & 6 & 0.0 & $0.0-0.0$ & 820 \\
\hline sAN(ABC) & 465 & 2.4 & $2.1-2.6$ & 869 & 19 & 0.1 & $0.1-0.1$ & 820 \\
\hline \multicolumn{9}{|l|}{ AN Binge and Purging subtype } \\
\hline AN & 37 & 0.2 & $0.1-0.3$ & 873 & nd & nd & nd & nd \\
\hline sAN & 67 & 0.4 & $0.3-0.5$ & 877 & nd & nd & nd & nd \\
\hline $\mathrm{AN}(\mathrm{ABC})$ & 62 & 0.3 & $0.3-0.4$ & 863 & 0 & 0.0 & $0.0-0.0$ & 820 \\
\hline sAN(ABC) & 138 & 0.8 & $0.6-0.9$ & 869 & 1 & 0.0 & $0.0-0.0$ & 820 \\
\hline
\end{tabular}

95\% CI: 95\% Confidence Interval, nd: not determined; ${ }^{\mathrm{f}}$ prevalence calculated with weighting for age, gender, and geographical region; ${ }^{*}$ International Cole's thinness criteria grade 2 and ${ }^{* *}$ International Cole's thinness criteria grade 3; AN: anorexia nervosa according to ABCD criteria based on DSM-IV and international Cole's thinness criteria grade 2; sAN: anorexia nervosa according to ABCD criteria based on DSM-IV and International Cole's thinness criteria grade 3; $\mathrm{AN}(\mathrm{ABC})$ : anorexia nervosa according to $\mathrm{ABC}$ criteria based on DSM-IV and International Cole's thinness criteria grade 2; sAN(ABC): anorexia nervosa according to ABC criteria based on DSM-IV and International Cole's thinness criteria grade 3.

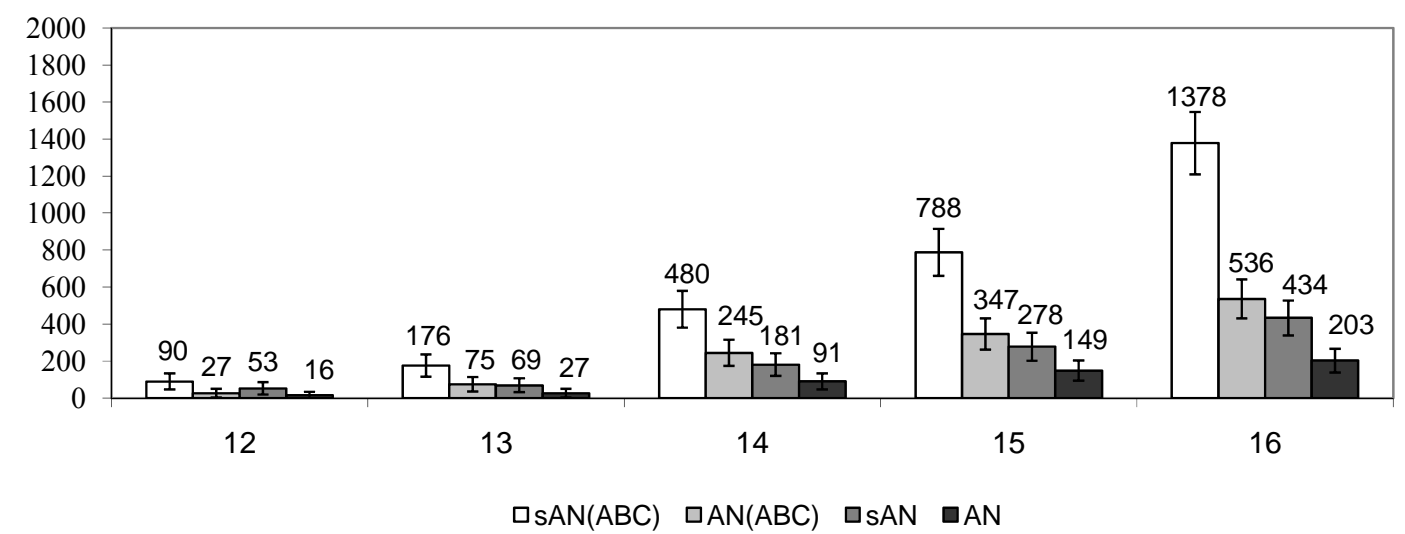

Figure 1. Incidence of new cases of AN subgroups per 100,000 girls at each age. 


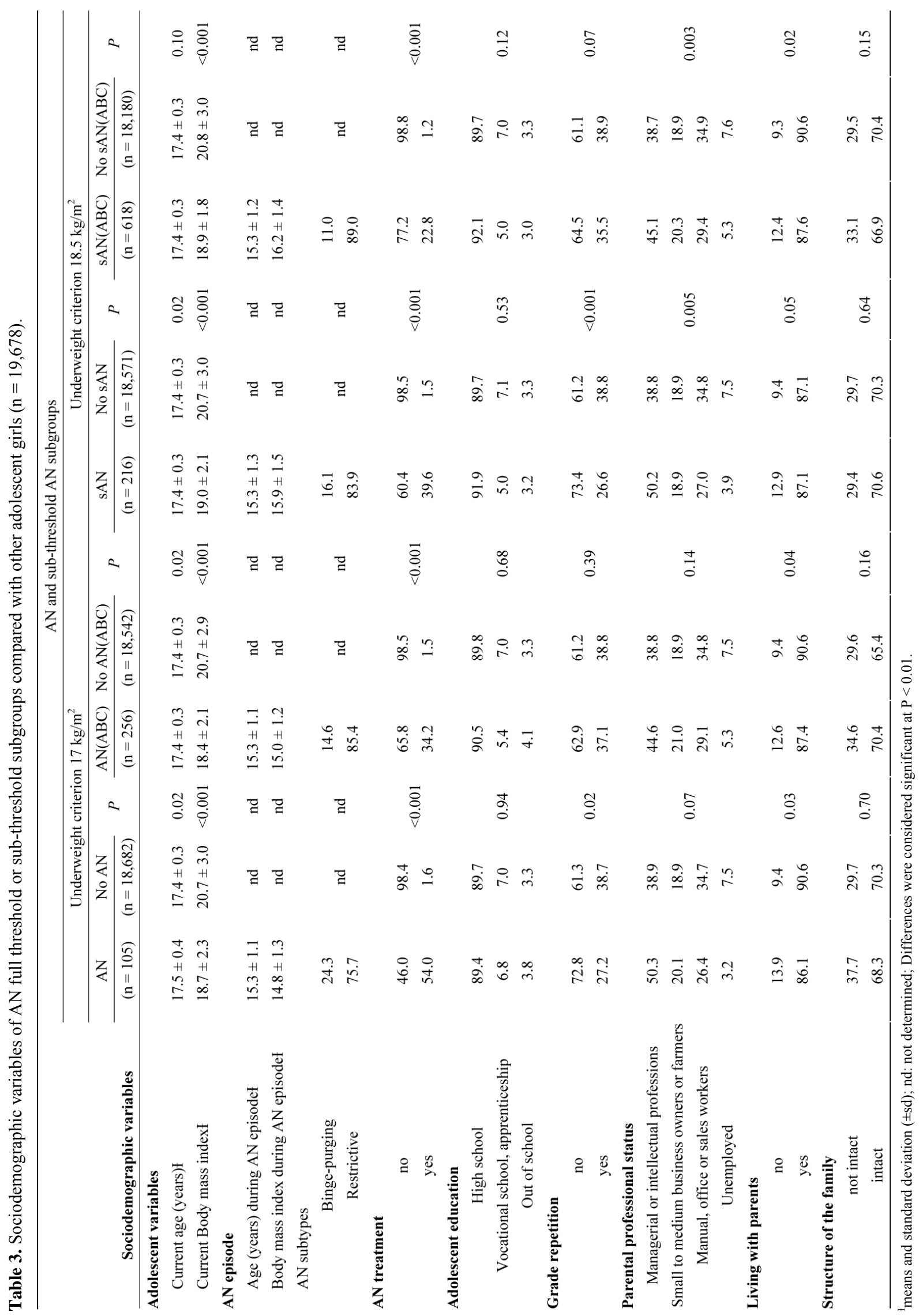




\section{DISCUSSION}

To our knowledge, this is the first study to assess AN prevalence using an international thinness criterion in a such a large adolescent community sample. In all, $0.5 \%$ of the girls reported severe AN based on Cole's international thinness cut-off $\left(17 \mathrm{~kg} / \mathrm{m}^{2}\right)$ between the ages of 12 and 17 years. Based on their reported answers, between $1.2 \%$ and $3.3 \%$ of girls were in the sub-threshold subgroups. The majority of them reported restrictive eating subtype $(75.7 \%$ to $89.0 \%)$. The incidence of AN was highest at age 16. The sub-threshold AN subgroup subjects more frequently came from families where the parents were in managerial or intellectual occupations rather than manual, office, or sales occupations, or unemployed. Half of the adolescents who scored for AN reported receiving treatment, and $22.8 \%$ to $39.6 \%$ of adolescents who scored for sub-threshold AN were also treated.

\subsection{Prevalence}

Young people more frequently meet only one AN criterion rather than all the criteria for AN. Like Ackard et al. [3], we found many young people who reported body shape perception disturbances $(42.6 \%$ for girls and $15.4 \%$ for boys), but only a few reported a diagnosis of AN. Finally, a large proportion of adolescent girls (12.2\%) reported amenorrhea lasting at least 3 months, as frequently described during adolescence [19]. Despite our strict AN weight threshold $\left(17 \mathrm{~kg} / \mathrm{m}^{2}\right)$, if we account for methodological differences, we find an AN prevalence for girls that is comparable to that of other studies. First, Ackard et al. [3] included young adolescents (between 14 and 15 years), so their AN prevalence $(0.04 \%)$ is likely to be lower than in our study. Second, two studies $[5,6]$ assessed AN lifetime prevalence $(0.48 \%$ and $0.9 \%$, respectively) among adults aged 18 years and older. Both these studies probably underestimate the AN prevalence due to recall bias, among older subjects especially, because their memory of earlier experiences may diminish with age. In our study, we focused on a high-risk age band, (12 - 17 years) where around $50 \%$ of AN occurs [5,6]. Third, Keski-Rahkonen and her colleagues [7] found a higher prevalence (2.2\%) compared to our study, for two major reasons: 1) their sample included the two high-risk age bands (before and after 18 years); and 2) they operationalized a broader weight threshold for AN defined as "anorexia nervosa without amenorrhea or weight loss of at least $15 \%$ that led to a body mass index $(\mathrm{BMI}) \leq 19$, coupled with undue influence of body weight on self-evaluation or intense fear of weight gain". Our study found a similar AN prevalence rate to that reported by Swanson et al. [4] who used a modified version of the Composite International Diagnostic Interview with adolescents $(0.3 \%$ at $13-18$ years of age).
For boys, AN prevalence is $0.03 \%(\mathrm{~N}=6)$, which is lower than in other studies $(0.24 \%$ to $0.30 \%)$ [6]. Puberty is considered as a risk or precipitating factor for eating disorders [20], and they may occur later in boys than girls [21]. Therefore, AN incidence could be delayed in boys, a factor that may explain why we observed a low prevalence between ages 12 and 17 in our sample. It is possible that the boys were not yet affected by AN because of a later age of onset [22]. Indeed, no AN boy was found in a sample of 14-year-olds [3]. A third important point is that the weight threshold criterion of Cole's grade 2 thinness is probably too low for boys. In our study, only $1.7 \%$ of the boys had a body weight below normal weight for age and height, compared to $3.4 \%$ of the girls. A $17 \mathrm{~kg} / \mathrm{m}^{2}$ BMI for boys corresponds to a level below the $3^{\text {rd }}$ percentile of growth curves, whereas it is between the $3^{\text {rd }}$ and $10^{\text {th }}$ percentile for girls [11].

\subsection{Incidence}

In our study, incidence rose for girls between the ages of 12 and 16, reaching its maximum level around age 16. The AN average incidence rate recorded here (97/ 100,000 persons/year) is well below that of $270 / 100,000$ reported by Keski-Rakhonen et al. [7]. However, their calculation concerned a different age range (15 to 19 years) and used a broader weight threshold for AN. Likewise, while our average incidence rates for sub-threshold AN subgroups are much higher than for AN (ranging from $202 / 100,000$ to $577 / 100,000$ ), they are in line with the $490 / 100,000$ incidence rate reported by KeskiRakhonen et al. [7].

\subsection{AN and Parental Socioeconomic Status}

To our knowledge, our study is the first epidemiological research in the general population that found a larger proportion of higher SES individuals in AN subgroups. Body dissatisfaction and desire for thinness is common in high-SES environments across the world [23], and a desire for thinness is a well-known risk factor for AN. Consequently, we hypothesize that social pressure to be slim is greater among adolescents from the higher socioeconomic groups, and could lead to a higher AN occurrence in high-SES predisposed subjects.

\subsection{Treatment Received}

Girls reporting AN demonstrate low levels of service utilization, as usually described $[5,24,25]$. This could result from two phenomena: 1) these subjects did not consult for their disorder due to the egosyntonic nature of their symptoms [5]; and/or 2) these subjects were not diagnosed by the professionals they consulted $[7,26]$. Like Preti et al. [5], we observed that AN subjects were 
twice as likely to be receiving treatment as those with sub-threshold disorders. The absence of certain criteria such as amenorrhea or extreme thinness makes subthreshold AN more difficult to detect by clinicians. This is an important public health issue because sub-threshold AN subjects have somatic and psychiatric complications that can be as severe as those of AN subjects [17,27-29].

\subsection{Strengths and Limitations}

This very large population-based sample of adolescents is representative of the French adolescent population, so our results can be generalized to this population. The mapping of AN criteria was conceptualized before designing the survey. We developed AN questions based on the four AN criteria of the DSM-IV. The main limitation is that the questionnaire used has not been validated in reference to a structured "gold standard" clinical interview. Diagnosis by self-report is widely used in epidemiological studies [30-32]. However, self-report instruments usually tend to overestimate prevalence rates of psychiatric diagnoses compared with interview-based instruments [33]. Self-reported weights and heights may also be biased due to the potentially sensitive nature of these measures among individuals with eating problems. Concerning self-reported BMI measures, studies have shown that AN patients were very accurate on their selfreported BMI $[34,35]$. Estimates for males from population-based studies are not robust because they involve small numbers of men with eating disorders (no more than 6 men with AN in any study).

\subsection{Implications and Contributions}

Overall, we confirm a marked prevalence of $\mathrm{AN}$ in the period since the $12^{\text {th }}$ birthday among girls assessed at age 17. In this age group, $A N$ adolescents were most often in a restrictive subtype. AN subjects are more likely to come from the higher socioeconomic categories. Only half of the self-reported AN subjects were receiving treatment for their eating problems. This suggests that clinicians should be better trained on these issues and that screening should be promoted to prevent potential complications. For future epidemiological studies, we suggest using Cole's thinness cut-off to define AN underweight criteria in DSM-V, and this could improve international comparability among studies.

\section{REFERENCES}

[1] Huas, C., Caille, A., Godart, N., Foulon, C., Pham-Scottez, A., Divac, S., Dechartres, A., Lavoisy, G., Guelfi, J.D., Rouillon, F. and Falissard B. (2011) Factors predictive of ten-year mortality in severe anorexia nervosa patients. Acta Psychiatrica Scandinavica, 123, 62-70. doi:10.1111/j.1600-0447.2010.01627.x
[2] Papadopoulos, F.C., Ekbom, A., Brandt, L. and Ekselius, L. (2009) Excess mortality, causes of death and prognostic factors in anorexia nervosa. British Journal of Psychiatry, 194, 10-17. doi:10.1192/bjp.bp.108.054742

[3] Ackard, D.M., Fulkerson, J.A. and Neumark-Sztainer, D. (2007) Prevalence and utility of DSM-IV eating disorder diagnostic criteria among youth. International Journal of Eating Disorders, 40, 409-417. doi:10.1002/eat.20389

[4] Swanson, S.A., Crow, S.J., Le Grange, D., Swendsen, J. and Merikangas, K.R. (2011) Prevalence and correlates of eating disorders in adolescents: Results from the national comorbidity survey replication adolescent supplement. Archives of General Psychiatry, 68, 714-723. doi:10.1001/archgenpsychiatry.2011.22

[5] Preti, A., Girolamo, G., Vilagut, G., Alonso, J., de Graaf, R., Bruffaerts, R., Demyttenaere, K., Pinto-Meza, A., Haro, J.M., Morosini, P. and ESEMeD-WMH Investigators (2009) The epidemiology of eating disorders in six European countries: Results of the ESEMeD-WMH project. Journal of Psychiatric Research, 43, 1125-1132. doi:10.1016/j.jpsychires.2009.04.003

[6] Hudson, J.I., Hiripi, E., Pope Jr., H.G. and Kessler, R.C. (2007) The prevalence and correlates of eating disorders in the National Comorbidity Survey Replication. Biological Psychiatry, 61, 348-358. doi:10.1016/j.biopsych.2006.03.040

[7] Keski-Rahkonen, A., Hoek H.W., Susser, E.S., Linna, M.S., Sihvola, E., Raevuori, A., Bulik, C.M., Kaprio, J., and Rissanen, A. (2007) Epidemiology and course of anorexia nervosa in the community. American Journal of Psychiatry, 164, 1259-1265.

doi:10.1176/appi.ajp.2007.06081388

[8] Hoek, H.W. and van Hoeken, D. (2003) Review of the prevalence and incidence of eating disorders. International Journal of Eating Disorders, 34, 383-396. doi:10.1002/eat.10222

[9] World Health Organisation (1992) The ICD-10 classification of mental and behavioural disorders: Clinical descriptions and diagnostic guidelines. WHO, Geneva.

[10] Hebebrand, J., Himmelmann, G.W., Heseker, H., Schafer, H. and Remschmidt, H. (1996) Use of percentiles for the body mass index in anorexia nervosa: Diagnostic, epidemiological, and therapeutic considerations. International Journal of Eating Disorders, 19, 359-369.

[11] Rolland-Cachera, M.F., Cole, T.J., Sempé, M., Tichet, J., Rossignol, C. and Charraud, A. (1991) Body Mass Index variations: Centiles from birth to 87 years. European Journal of Clinical Nutrition, 45, 13-21.

[12] Cole, T.J., Flegal, K.M., Nicholls, D. and Jackson, A.A. (2007) Body mass index cut offs to define thinness in children and adolescents: International survey. British Medical Journal, 335, 194. doi:10.1136/bmj.39238.399444.55

[13] Beck, F., Legleye, S. and Peretti-Watel, P. (2000) Les usages de substances psychoactives à la fin de l'adolescence: Mise en place d'une enquête annuelle [The use of psychoactive substances among adolescents in their late teens-Setting up an annual survey]. Tendances, 10, pp. 
$1-4$.

[14] INSEE (2011) Bulletin statistique. http://www.indices.insee.fr/

[15] Beck, F., Costes, J.-M., Legleye, S., Peretti-Watel, P. and Spilka, S. (2006) ESCAPAD survey on the use of Drugs: An original collection device on a sensitive topic, In: Lavallée, P. and Rivest, L-P., Eds. Survey Methods: European and North American practices, Dunod, Paris, 5659.

[16] American Psychiatric Association (1994) Statistical manual of mental disorder. 4th Edition, American Psychiatric Press, Washington DC.

[17] Attia, E. and Roberto, C.A. (2009) Should amenorrhea be a diagnostic criterion for anorexia nervosa? International Journal of Eating Disorders, 42, 581-589. doi:10.1002/eat.20720

[18] National Institute of Statistics and Economic Studies (INSEE) (2003) Classification of occupations and socioprofessional categories (OSC): List of aggregated socioprofessional categories.

[19] Billewicz, W.Z., Fellowes, H.M. and Thomson, A.M. (1980) Post-menarcheal menstrual cycle in British (Newcastle upon Tyne) girls. Annals of Human Biology, 7, 177-180. doi:10.1080/03014468000004201

[20] Klump, K.L., Burt, S.A., McGue, M. and Iacono, W.G. (2007) Changes in genetic and environmental influences on disordered eating across adolescence: A longitudinal twin study. Archives of General Psychiatry, 64, 14091415. doi:10.1001/archpsyc.64.12.1409

[21] de la Rochebrochard, É. (1999) Age of puberty onset among French girls and boys. Measures based on a survey on adolescent sexuality. Population, 54, 933-962. doi: $10.2307 / 1534716$

[22] Forman-Hoffman, V.L., Watson, T.L. and Andersen, A.E. (2008) Eating disorder age of onset in males: distribution and associated characteristics. Eating and Weight Disorders, 13, e28-e31.

[23] Swami, V., Frederick, D.A., Aavik, T., Alcalay, L., Allik, J., Anderson, D., Andrianto, S., Arora, A., Brännström, A., Cunningham, J., Danel, D., Doroszewicz, K., Forbes, G.B., Furnham, A., Greven, C.U., Halberstadt, J., Hao, S., Haubner, T., Hwang, C.S., Inman, M., Jaafar, J.L., Johansson, J., Jung, J., Keser, A., Kretzschmar, U., Lachenicht, L., Li, N.P., Locke, K., Lönnqvist, J.E., Lopez, C., Loutzenhiser, L., Maisel, N.C., McCabe, M.P., McCreary, D.R., McKibbin, W.F., Mussap, A., Neto, F., Nowell, C., Alampay, L.P., Pillai, S.K., Pokrajac-Bulian, A., Proyer, R.T., Quintelier, K., Ricciardelli, L.A., Rozmus-Wrzesinska, M., Ruch, W., Russo, T., Schütz, A., Shackelford, T.K., Shashidharan, S., Simonetti, F., Sinniah, D., Swami, M., Vandermassen, G., van Duynslaeger, M., Verkasalo, M., Voracek, M., Yee, C.K., Zhang, E.X., Zhang, X. and Zivcic-Becirevic, I. (2010) The attractive female body weight and female body dissatisfaction in 26 countries across 10 world regions: Results of the international body project I. Personality and Social Psychology Bulletin, 36, 309-325. doi:10.1177/0146167209359702

[24] Fairburn, C.G. and Harrison, P.J. (2003) Eating disorders.
Lancet, 361, 407-416. doi:10.1016/S0140-6736(03)12378-1

[25] Halmi, K.A., Agras, W.S., Crow, S., Mitchell, J., Wilson, G.T., Bryson, S.W. and Kraemer, H.C. (2005) Predictors of treatment acceptance and completion in anorexia nervosa: Implications for future study designs. Archives of General Psychiatry, 62, 776-781. doi:10.1001/archpsyc.62.7.776

[26] Hoek, H.W. (1991) The incidence and prevalence of anorexia nervosa and bulimia nervosa in primary care. Psychological Medicine, 21, 455-460. doi:10.1017/S0033291700020560

[27] Johnson, J.G., Cohen, P., Kasen, S. and Brook, J.S. (2002) Eating disorders during adolescence and the risk for physical and mental disorders during early adulthood. Archives of General Psychiatry, 59, 545-552. doi:10.1001/archpsyc.59.6.545

[28] Patton, G.C., Coffey, C., Carlin, J.B., Sanci, L., Sawyer, S. (2008) Prognosis of adolescent partial syndromes of eating disorder. British Journal of Psychiatry, 192, 294299. doi:10.1192/bjp.bp.106.031112

[29] Thomas, J.J., Vartanian, L.R. and Brownell, K.D. (2009) The relationship between eating disorder not otherwise specified (EDNOS) and officially recognized eating disorders: Meta-analysis and implications for DSM. Psychological Bulletin, 135, 407-433. doi: $10.1037 / \mathrm{a} 0015326$

[30] Jayasekera, H., Carter, G. and Clover, K. (2011) Comparison of the Composite International Diagnostic interview (CIDI-Auto) with clinical diagnosis in a suicidal population. Archives of Suicide Research, 15, 43-55. doi:10.1080/13811118.2011.540208

[31] Kedzior, K.K. and Martin-Iverson, M.T. (2007) Concurrent validity of cannabis misuse diagnoses on CIDI-Auto 2.1 in low-level cannabis users from the general population. Australian Journal of Psychology, 59, 169-175.

[32] Rosenman, S.J., Korten, A.E. and Levings, C.T. (1997) Computerised diagnosis in acute psychiatry: Validity of CIDI-Auto against routine clinical diagnosis. Journal of Psychiatric Research, 31, 581-592. doi:10.1016/S0022-3956(97)00032-0

[33] Sunderland, M., Andrews, G., Slade, T. and Peters, L. (2011) Measuring the level of diagnostic concordance and discordance between modules of the CIDI-Short Form and the CIDI-Auto 2.1. Social Psychiatry and Psychiatric Epidemiology, 46, 775-785. doi:10.1007/s00127-010-0247-6

[34] McFarlane, T., McCabe, R.E., Jarry, J., Olmsted, M.P., and Polivy, J. (2001) Weight-related and shape-related self-evaluation in eating-disordered and non-eating-disordered women. International Journal of Eating Disorders, 29, 328-335. doi:10.1002/eat.1026

[35] McCabe, R.E., McFarlane, T., Polivy, J. and Olmsted, M.P. (2001) Eating disorders, dieting, and the accuracy of self-reported weight. International Journal of Eating Disorders, 29, 59-64. doi:10.1002/1098-108X(200101)29:1<59::AID-EAT9>3. $\underline{0 . \mathrm{CO} ; 2-\#}$ 